\title{
Questão racial e esfera pública virtual: uma análise do site da Secretaria de Políticas de Promoção da Igualdade Racial
}

\section{Alicianne Gonçalves de Oliveira e Alexandre Barbalho}

\section{Resumo}

0 presente artigo busca compreender como 0 órgão do Executivo Federal brasileiro ligado à questão racial age na esfera pública virtual. Para isso, analisa o site da Secretaria de Políticas de Promoção da Igualdade Racial (SEPPIR), ligada à Presidência da República. A intenção é avaliar a contribuição desse site na possível formação de esferas de visibilidade e discutibilidade públicas. Este trabalho também analisa se essa experiência estatal atende aos requisitos democráticos a serem cumpridos pela interface digital do Estado: publicidade, responsividade e porosidade. Para tanto, é feita uma avaliação qualitativa do site. Também recorre-se a entrevista feita com a profissional responsável pelo veículo estudado.

\section{Palavras-Chave}

Esfera pública virtual. Governo Federal. Questão racial.
Alicianne Gonçalves de Oliveira I alicianneg@ gmail.com

Mestre em Comunicação pela Universidade Federal do Ceará (UFC). Jornalista da Universidade Federal do Ceará (UFC).

Alexandre Barbalho I alexandrealmeidabarbalho@ gmail.com

Doutor em Comunicação e Cultura Contemporâneas pela Universidade Federal da Bahia (UFBA). Professor do Programa de Pós-Graduação em Comunicação da Universidade Federal do Ceará (UFC) e do Programa de Pós-Graduação em Políticas Públicas da Universidade Estadual do Ceará (UECE)

\section{Introdução}

A Secretaria de Políticas de Promoção da Igualdade Racial (SEPPIR), órgão ligado diretamente à Presidência da República do Brasil, foi criada em 2003 com a missão de promover e articular ações que promovam a igualdade e a proteção dos direitos de indivíduos e de grupos raciais e étnicos afetados pela discriminação e demais formas de intolerância.

Para pautar o tema da igualdade racial, a SEPPIR produz material publicitário sobre seus projetos, mantém um canal no Youtube, perfis no Twitter e no Facebook, elabora o Notícias SEPPIR, publicação digital que traz informações sobre a Secretaria e sobre a temática racial, e produz um boletim semestral. Mas o veículo pelo qual a Secretaria dá, em maior grau, publicidade às suas ações e ao debate racial é o site oficial do órgão www.seppir.gov.br.

Este artigo analisa o referido site com o objetivo de compreender como a Secretaria se coloca na esfera pública virtual. Interessa identificar a 
participação dessa experiência estatal na possível formação de uma esfera de visibilidade política e de uma esfera de discutibilidade pública, promovendo o debate e 0 diálogo com a ampliação ou a incorporação de novos temas, problemas e questões. Nesse caminho, a questão é perceber se 0 site da SEPPIR atende às exigências ou requisitos democráticos a serem cumpridos por uma interface digital do Estado: publicidade, responsividade e porosidade.

Para alcançar os objetivos propostos, como procedimento metodológico optamos por realizar uma avaliação qualitativa do site, o diagnóstico das características técnicas do veículo, o estudo das iniciativas de visibilidade e discutibilidade, bem como as de publicidade, responsividade e porosidade. De forma secundária, recorremos à entrevista feita com a coordenadora do setor de comunicação da SEPPIR, a jornalista Jucinete Maria Machado. A entrevista semiestruturada abordou, entre outros assuntos: a estrutura do site; o processo de produção de conteúdo; a utilização de instrumentos de informação e participação; os grupos contemplados no site; a avaliação geral que a equipe de comunicação faz desta ferramenta de comunicação.

0 artigo estrutura-se em quatro partes. $\mathrm{Na}$ primeira, estabelecemos o debate conceitual de espaço público e de democracia virtuais. Em seguida, analisamos, mesmo que rapidamente, experiências de esfera pública virtual e democracia digital no Brasil. Na terceira parte, nos concentramos na avaliação da contribuição do site da SEPPIR para uma esfera pública virtual em torno do debate racial. Por fim, estabelecemos algumas conclusões que resultaram da pesquisa.

\section{Esfera pública $\mathrm{e}$ democracia em tempo digital}

Uma das contribuições da internet e de outras tecnologias digitais de informação e comunicação para 0 campo da política é o que se chama de democracia digital, e-democracy ou ciberdemocracia. Tal ideia se relaciona, entre outras, com a noção de e-government ou governo eletrônico, apontado por Lévy (2003) como um dos primeiros passos de uma nova democracia, advinda da esfera pública virtual.

\section{0 e-government seria 0 Estado seguindo 0} movimento da economia e colocando online suas informações e seus serviços, reduzindo custos operacionais, agilizando trâmites burocráticos e proporcionando maior integração com parceiros e cidadãos (LEMOS; ROCHA, 2007). Mas o grande desafio que a internet e os novos medias trazem ao poder público não é ser mais transparente ou colocar informações e serviços na internet e sim usufruir as possibilidades proporcionadas pelo meio no tocante ao relacionamento com os cidadãos no sentido de implantar uma democracia digital.

Apoiando-se em Gomes (2011, p. 27-28), entendese por democracia digital qualquer forma de uso 
de dispositivos, ferramentas e aplicativos digitais de comunicação "[...]para suplementar, reforçar ou corrigir aspectos das práticas políticas e sociais do Estado e dos cidadãos, em benefício do teor democrático da sociedade política". Ou seja, considera-se, nessa definição, o uso de computadores, celulares, tablets, variados programas, e diversas ferramentas, como redes sociais, fóruns e sites. Essas ferramentas, dispositivos e aplicativos podem e devem ser usados por vários atores e arenas sociais do Estado e da sociedade civil.

Mas como saber se as iniciativas e os usos da democracia digital estão realmente suplementando, reforçando ou corrigindo aspectos das práticas políticas e sociais do Estado e dos cidadãos e beneficiando a democracia? Gomes (2011) fala que para as iniciativas digitais serem democraticamente relevantes elas devem buscar pelo menos um desses propósitos: 1) consolidação e reforço dos direitos e liberdades; 2) aumento do pluralismo na esfera pública, na esfera de decisão e aumento do poder das minorias; 3) aumento do poder civil.

Jensen (2003) explica que há perspectivas diferentes quando o assunto é como chegar ao fortalecimento da esfera pública e da democracia através da internet. Há os que defendem 0 argumento laissez-faire, deixando que a internet crie, por si mesma, as condições de discurso ideal, e há os que defendem que os governos devem agir, criar fóruns de debates, garantindo o livre e 0 igual acesso às discussões.
A segunda perspectiva é a defendida por Gomes (2007) quando afirma que uma esfera pública democrática não existe por si mesma, mas é tarefa inclusive do Estado. As instituições do Estado devem estar dispostas, por exemplo, a prover informações, oferecer mecanismos adequados de participação e prover a motivação.

Essas ideias se alinham ao que Silva (2011) chama de exigências democráticas para a interface digital do Estado: publicidade, responsividade e porosidade. Um portal governamental, por exemplo, consegue preencher o requisito da publicidade quando agrupa um conjunto de informações institucionais, financeiras, políticas e administrativas que é vasto, diversificado, relevante, e fica disponível virtualmente para um número considerável de cidadãos e em diversas linguagens.

Já a exigência da responsividade significa tornar o Estado, de algum modo, mais dialógico e pode ser materializada na forma de serviços on-line, dispositivos para dar respostas informativas, e interação dialógica mais densa, proporcionada pela interação entre os cidadãos e representantes do Estado, usando os chats ou fóruns de discussão.

A terceira exigência, a porosidade, quer dizer um Estado mais aberto à opinião pública na produção da decisão política, portanto, "[...] é o requisito democrático que mais incorpora as demandas de participação" (SILVA, 2011, p. 132). Ele pode ser 
alcançado através de mecanismos como 0 voto on-line, sondagens de opinião, consultas públicas feitas virtualmente.

Essas três exigências se complementam e se influenciam, mas podem ser desenvolvidas em graus diferentes. Hoje, por exemplo, a publicidade é a exigência mais desenvolvida, de modo que 0 atual desafio, nesse processo, não é ser mais transparente, colocando informações e serviços na internet, e sim aumentar o grau de responsividade e porosidade, e, com isso, aumentar o poder de influência dos cidadãos sobre a esfera de decisão. Como fala Bohman (2004, p. 135, tradução nossa), "[...] há uma falta de congruência entre as instituições políticas existentes e 0 amplo potencial de interação comunicativa do público" ${ }^{1}$

\section{Esfera pública virtual e democracia digital no Brasil}

No Brasil, onde 67,9 milhões de pessoas, de dez anos ou mais, ou seja mais de $41 \%$ da população brasileira em 2009, acessam a internet, ${ }^{2}$ como se dão as práticas de esfera pública virtual e democracia digital? (IBGE, 2010)

No âmbito do Poder Legislativo, o Portal da Câmara dos Deputados é considerado uma das mais importantes experiências de democracia digital no país. Segundo Marques (2008), as informações disponibilizadas são relevantes no sentido de fomentar a participação da esfera civil. Ele permite que os acontecimentos políticos ganhem mais visibilidade e que as atividades dos deputados e da instituição sejam fiscalizadas.

0 Portal da Câmara também é exitoso quanto ao uso dos canais de participação. Dentre as possibilidades que 0 cidadão tem no Portal, destacam-se os fóruns públicos, que também reúnem eleitores e parlamentares e representam um espaço de discussão mais profunda, onde pode haver "um envolvimento político mais próximo entre esfera dos representantes e esfera civil" (MARQUES, 2011, p. 108).

Uma iniciativa estatal, agora desenvolvida pelo Poder Executivo, é o uso amplo, nos últimos anos, da internet com o objetivo de promover a participação da população em Orçamentos Participativos, uma espécie de OP digital, usado para reforçar e/ou complementar 0 modelo tradicional (BEST et al., 2010). Outra iniciativa é a das cidades digitais. 0 projeto, sob responsabilidade da Secretaria de Inclusão Social, pretende levar internet para 0 cotidiano das cidades por meio do Programa Nacional de Banda Larga. Para tanto, a administração dos municípios beneficiados precisa ter iniciativas de governo

"At present, there is a lack of congruity between existing political institutions and the wider potential for public communicative interaction".

A pesquisa considerou o uso da internet feito apenas através de computador, não sendo considerados acessos através de telefone celular e outros dispositivos. 
eletrônico e locais onde as pessoas possam acessar a internet de forma gratuita. ${ }^{3}$

Contudo, ainda no que diz respeito ao Poder Executivo, Silva (2005) realizou um estudo sobre como os portais das administrações das capitais brasileiras usavam as novas tecnologias de comunicação e informação no relacionamento com os cidadãos. 0 autor concluiu que, de uma forma geral, os governos das maiores cidades brasileiras exercem uma democracia digital elementar. A base das iniciativas é a informação, seguida da prestação de serviços públicos, com concentração na área tributária. Não existem aberturas efetivas para a participação dos cidadãos nos negócios públicos de modo que a internet não é usada para aumentar o poder da esfera civil na produção da decisão pública.

No caso dos estados brasileiros, a realidade não é tão diferente. Pinho (2008) analisou os portais do Distrito Federal e de nove estados (Bahia, Rio Grande do Sul, São Paulo, Minas Gerais, Rio de Janeiro, Paraná, Pernambuco, Santa Catarina e Goiás) com o objetivo de verificar se e como os governos e seus portais poderiam ser considerados uma experiência de aprofundamento democrático e de realização de uma sociedade digital. Para 0 autor, o problema dos estados brasileiros não é tecnologia, mas de cultura política: faltam transparência e diálogo aberto com o público, bem como instrumentos de accountability e participação popular. ${ }^{4}$

No âmbito do Executivo Federal, portais de ministérios, secretarias e demais órgãos da administração direta já incorporaram a necessidade e o dever de expor as informações e ofertar serviços. 0 país possui um programa de Governo Eletrônico, desde 0 ano de 2000, cujos objetivos são: democratizar o acesso à informação; ampliar discussões; dinamizar a prestação de serviços públicos com foco na eficiência e efetividade das funções governamentais. ${ }^{5}$

Se a maior parte do Programa concentra-se no acesso aos serviços e às informações, dentro de sua estrutura há também ferramentas de participação dos cidadãos, como os fóruns e as consultas. ${ }^{6}$ Um canal de participação do cidadão que já é usado por alguns órgãos da administração direta do Poder Executivo é a Consulta Pública On-line (CP0). Segundo Matheus (2009), nove dos 23 ministérios existentes até a data de sua

Informações disponíveis na ConexãoMiniCom, revista eletrônica do Ministério das Comunicações. Disponível em: <http://www. conexaominicom.mc.gov.br/index.php/component/content/article/34-post/248-projeto-cidades-digitais-e-uma-das-prioridades-doministerio-das-comunicacoes>. Acesso em 24 ago. 2011.

A pesquisa de Lima (2012) sobre o portal do governo de Roraima chegou às mesmas conclusões de Pinho.

Ministério do Planejamento, Orçamento e Gestão. Portal do Governo Eletrônico. Disponível em:<http://www.governoeletronico. gov.br/acoes-e-projetos>. Acesso em 20 ago. 2011.

De maio de 2004 a agosto de 2010, o portal realizou 37 CP0s que obtiveram 1.249 contribuições. 
pesquisa apresentavam o modelo de consulta pública on-line em seu histórico. Para Rothberg (2008, p. 167), as consultas "[...] proporcionam interação com o processo de produção de políticas de grandes consequências [...]", o que indica "[...] que 0 Estado brasileiro assumiu a função de utilizar a rede em benefício da ampliação dos locais onde se realiza a democracia no país".

No caso específico do Portal da Presidência da República (desde 2011, Portal do Planalto), Marques avalia que ele atua "[...] mais como um grande repositório de informações institucionais e de promoção dos dirigentes de suas secretarias e órgãos" (MARQUES, 2008, p. 320). Portanto, o Portal da Presidência da República não consegue aproveitar as possibilidades que a internet proporciona. Mesmo diante desse quadro, o autor faz uma ressalva importante em relação à experiência do Governo Federal ao reconhecer o Portal da Transparência e as páginas de Transparência Pública como "[...] canais adicionais de controle e fiscalização na gestão da coisa pública" (MARQUES, 2008, p. 320).

Se 0 acesso à informação é importante para reforçar a esfera pública e deve ser uma prioridade nas iniciativas digitais democraticamente relevantes (GOMES, 2011), tal procedimento não pode dispensar canais de comunicação que sejam interativos, participativos, para tornar o Estado mais responsivo e poroso. 0 índice considerável de participação em algumas iniciativas digitais desenvolvidas pelo Estado indica que os cidadãos anseiam por serem considerados no momento da decisão política. E, como defende Miola (2011), as condições para 0 aperfeiçoamento da articulação comunicativa dos cidadãos e sua qualificação como deliberação pública só vão ser possíveis com a oferta e a prática constante desse diálogo.

Dentro desse contexto, podemos acompanhar a realidade da SEPPIR, ou seja, se o seu site responde aos anseios de participação do cidadão quando se trata de questões raciais. Trata-se de um locus privilegiado de análise posto que a criação da Secretaria resultou da pressão do movimento negro que, com diferentes objetivos e estratégias, procurou ser ouvido e influenciar nos processos decisórios do Estado brasileiro. Portanto, movimento social e esfera governamental traçam uma história de conflitos, pressões, tentativas de aproximação e diálogo. ${ }^{7}$ Nessa perspectiva, seria legítimo inferir que o órgão estaria mais propenso a contribuir de forma mais efetiva através de sua principal ferramenta de comunicação digital para uma esfera pública virtual, reforçando práticas democráticas. É o que veremos no próximo tópico.

\section{Site da SEPPIR: 0 debate racial na esfera pública virtual}

Átila Roque (2009, p. 261), ao falar sobre 0 racismo e 0 antirracismo na sociedade brasileira, 
considera que o silêncio em relação ao racismo no país fez com que os negros brasileiros fossem condenados a uma espécie de "solidão civil" provocada por uma série de discriminações. Conforme 0 autor, isso aconteceu porque "[...] a esfera pública construída pela nossa limitada democracia não tinha espaço para o tema racial".

Só muito recentemente, a questão racial foi colocada em pauta a partir da atuação do movimento negro brasileiro. Como observa Costa (2002), ao longo do século XX, o movimento se constituiu e atuou na nossa esfera pública pautando suas questões e alargando as fronteiras temáticas dessa esfera. Daí a importância de discutir o papel que o site da SEPPIR desempenha na esfera pública virtual quando o tema é a questão racial.

Nosso interesse é compreender, até que ponto, 0 site se mostra comprometido não apenas com a publicidade, expondo suas ações e informações das mais diversas áreas ao maior número de cidadãos e através de diversas linguagens, mas em que medida também é responsivo, estabelecendo canais de diálogo com o cidadão, e se mostra poroso, abrindose, efetivamente, à opinião da sociedade.

Procederemos, então, à análise de como funciona 0 www.seppir.gov.br, atentos, como indica Thompson (1999), às situações espaço-temporais (local e tempo da comunicação da SEPPIR); aos campos envolvidos nessa produção (tecnológico, comunicacional e político); e aos meios técnicos.

Como a SEPPIR é um órgão da Presidência da República, o seppir.gov.br nasceu ligado ao Portal da Presidência, sob responsabilidade da Secretaria de Comunicação Social (SECOM). Mas, como informa Jucinete Machado, essa relação não existe desde meados de 2010, quando os sites de órgãos ligados à Presidência ficaram independentes, não só na produção de conteúdo, que já acontecia, mas, inclusive, com endereços próprios e com a possibilidade de pensarem seu layout. ${ }^{8}$

Contudo, 0 site da SEPPIR ainda segue 0 formato de quando era ligado ao antigo Portal da Presidência. Ele possui um menu generoso em tópicos informativos, dados sobre setores específicos da Secretaria e tópicos relacionados ao contato com 0 cidadão. 0 site sempre foi mantido pela equipe de Comunicação Social da Secretaria que também tem como funções 0 assessoramento direto do Ministro, a produção de material de propaganda e a atualização da página da secretaria no Facebook, do perfil do órgão no Twitter e do canal no Youtube. A equipe ainda é responsável por um boletim semestral e pelo Notícias SEPPIR.

0 setor é enxuto, formado, até dezembro de 2011, por uma estagiária e quatro funcionárias: uma jornalista, que também é coordenadora do setor; 
uma funcionária responsável pelo suporte técnico; uma secretária e uma auxiliar técnica. Diante dessa composição, quem produz e decide 0 que vai ou não ser veiculado no site é a coordenadora do setor. Segundo Machado, hoje a SEPPIR não tem estrutura física, recursos materiais e recursos humanos suficientes para desenvolver, de forma satisfatória, suas atribuições, ${ }^{9} 0$ que traz consequências para a forma como o seppir.gov.br se apresenta na esfera pública virtual.

Um dos elementos relacionados à noção de esfera pública é o de visibilidade pública, "[...] a cena ou o proscênio social, aquela dimensão da vida social [...] que é visível, acessível, disponível ao conhecimento e domínio públicos" (GOMES, 2008, p. 134). Segundo Jensen (2003), a esfera pública deve fazer com que os cidadãos reflitam e deve prover esses cidadãos com novas e relevantes informações sobre as questões políticas.

Em relação à visibilidade, 0 site da SEPPIR segue o padrão dos sites de órgãos vinculados à Presidência da República. 0 menu principal traz informações sobre 0 gestor, a estrutura da secretaria e as ações desenvolvidas. 0 conteúdo dos tópicos evidencia um esforço em levar ao cidadão uma grande quantidade de informações sobre agenda, estrutura e ações da Secretaria. De uma forma geral, 0 cidadão tem uma visão satisfatória do que 0 Governo Federal realiza quando o tema é políticas de promoção da igualdade racial. Mas há limitações e lacunas e a principal é a falta de atualização do site.

Silva (2011) explica que um portal governamental preenche o requisito da publicidade quando agrupa um conjunto de informações institucionais, financeiras, políticas e administrativas de forma vasta, diversificada, relevante, ficando disponível virtualmente para um número considerável de cidadãos e em diversas linguagens.

Em relação à publicidade, 0 site da SEPPIR apresenta exemplos de todos os tipos de níveis qualitativos com os quais os requisitos democráticos para a interface digital do Estado podem ser analisados, segundo Silva (2011): 1) nível argumentativo; 2) nível instrutivo; 3) nível informativo; 4) nível utilitário. 0 quinto nível, 0 decisório, não está relacionado diretamente às iniciativas de publicidade.

0 site da Secretaria apresenta ferramentas de busca e mapa do site (nível 1); torna o órgão mais transparente ao cidadão com a disponibilização de notícias e informativos (nível 2); torna o órgão mais visível ao cidadão ao fornecer informações sobre a história, a organização e o funcionamento da secretaria (nível 3); torna a SEPPIR mais visível e transparente através de uma relação argumentativa quando disponibiliza relatórios de gestão e de projetos e publicações sobre programas (nível 4). 
Assim, o seppir.gov.br, dentro das suas limitações, dá ao cidadão ferramentas que podem ajudar, por exemplo, no fortalecimento da cidadania. 0 site consegue atingir o requisito da publicidade, mas poderia alcançá-lo de um modo bem mais eficiente se a realidade de pessoal do órgão assim permitisse. É importante tornar essas informações visíveis ao cidadão, mas é preciso buscar um nível maior de organização e atualização.

Mas para que a esfera pública seja adequada à comunicação de conteúdos, bem como a tomadas de posição e opiniões (HABERMAS, 2003), é preciso discussão pública. Como explica Dean (2003), o debate traz consigo alguns pressupostos: igualdade, transparência, inclusão e racionalidade. Além disso, as trocas comunicativas devem permitir o intercâmbio entre os papéis de emissor do discurso e ouvinte. Com as tecnologias digitais de comunicação, mais especificamente a internet, há toda uma expectativa pela ampliação da fala pública.

A internet, com características como liberdade, inclusão e transparência, é vista como tendo potencial para "[...] revolucionar a comunicação política e a natureza da expressão e formação da opinião pública" (SAVIGNY, 2002, p. 5). E, mesmo que as discussões que não tenham um caráter deliberativo, elas podem ser importantes na medida em que são um meio de formação de opinião. E isso se coloca apesar das críticas sobre 0 nível e a qualidade das discussões na internet (PAPACHARISSI, 2002); das ressalvas em relação à interatividade proposta pelos novos meios (MAZZOLENI, 2001); e também das críticas procedentes à inclusão propalada pelos mais otimistas (CASTELLS, 2003).

No que diz respeito à ampliação do espaço de discussão na esfera pública virtual, o site da SEPPIR traz iniciativas modestas quanto ao uso de suas potencialidades. Dentro dos requisitos democráticos colocados por Silva (2011) para a interface digital do Estado, dois se ligam diretamente à questão da discutibilidade e da participação. São a responsividade e a porosidade. Ser responsivo significa ser, de alguma forma, dialógico, e porosidade se refere a estar aberto à opinião pública. São requisitos cujo fluxo de comunicação, ao contrário da publicidade, também parte da sociedade.

0 seppir.gov.br não apresenta níveis consideráveis de responsividade. De um modo geral, não estimula a discussão entre Estado e internautas. Dos níveis qualitativos apontados por Silva (2011) para esse requisito (utilitário, informativo, instrutivo e argumentativo), apenas um é contemplado pela experiência da SEPPIR. 0 site não disponibiliza serviços online, onde 0 cidadão obtém a resposta para sua demanda em forma de serviços (nível utilitário); não possui ferramentas, como chats, fóruns e listas de discussões com o objetivo de esclarecer sobre alguma ação ou atividade (nível instrutivo); não possui essas mesmas ferramentas, mas com caráter deliberativo, a fim de deliberar sobre algo, ouvir os 
argumentos do cidadão, sobre os quais o Estado precisa se posicionar (nível argumentativo). 0 nível contemplado no site da SEPPIR é o nível informativo, que se caracteriza pela utilização de e-mail, formulários para tirar dúvidas e chats fechados de cunho informativo.

A única forma de contato entre 0 cidadão $\mathrm{e}$ a Secretaria é o e-mail. Sem fornecer dados, Machado informa que a Secretaria recebe uma grande quantidade de e-mails, sendo a maioria das mensagens com caráter de denúncia, mas as pessoas também escrevem sobre questões que estão sendo debatidas no momento ${ }^{10}$. Contudo, há algumas ressalvas que devem ser feitas em relação ao e-mail.

Marques (2011, p. 109) afirma que o e-mail é um canal que não é suficiente para fomentar uma maior aproximação entre cidadãos e instituições representativas. Isso porque a interação "[...] acontece, na maioria das vezes, entre agentes políticos e indivíduos isolados, dificultando, assim, a constituição de espaços públicos de visibilidade e de discussão". Assim, o uso dessa ferramenta deixa 0 representante "[...] menos exposto ao escrutínio público e à prestação de contas”.

0 terceiro requisito democrático de que fala Silva (2011), a porosidade, reporta-se a um Estado mais aberto à opinião pública, mais suscetível ao cidadão, aberto à criação de inputs na produção da decisão política, por isso, é o que mais incorpora as demandas de participação, alcançada por meio de mecanismos como o voto on-line, sondagens de opinião, consultas públicas virtuais. Para esse requisito, também são colocados os quatro tipos de relações comunicativas ou níveis qualitativos utilizados para os outros dois requisitos. Mas há ainda um quinto nível, ligado somente ao requisito da porosidade: 0 nível decisório. Seria o Estado mais suscetível ao cidadão, em uma relação onde ele recebe as posições, que são tratadas como ordem, como tomada de decisão.

No site da SEPPIR não há qualquer nível de porosidade que permita aos cidadãos participarem plenamente da produção da decisão política. Assim, esse veículo de comunicação não seria um portal governamental completo, pois para um portal chegar a essa completude é preciso dar transparência às ações do Estado e cumprir o requisito da publicidade, mas também, "[...] concomitantemente, sustentar canais robustos de diálogo com os cidadãos (responsividade) e propiciar modos de incorporar a opinião destes no processo de decisão política (porosidade).” (SILVA, 2011, p. 134).

\section{Considerações finais}

A análise do site da Secretaria de Políticas de Promoção da Igualdade Racial - 0 www.seppir. 
gov.br, possibilitou saber como o Governo Federal coloca-se na esfera pública virtual, principalmente quando o tema é a questão racial no Brasil.

0 seppir.gov.br segue uma estrutura semelhante a da maioria dos sites de órgãos ligados à Presidência da República. A estrutura é rígida, sofre com a falta de atualização de informações e os exemplos de desorganização de dados não são raros. Mesmo assim, ressaltamos a tentativa e 0 relativo sucesso de tornar visíveis, públicas, transparentes as atividades, os dados sobre 0 dia a dia da gestora e da Secretaria como um todo e de publicizar informações acerca da temática racial no país. 0 site consegue, apesar das lacunas e falhas, atingir o requisito da publicidade, apontado por Silva (2011).

No entanto, o site é limitado quando os critérios dizem respeito ao debate, ao diálogo, que são característicos da esfera pública. As melhoras na relação entre Estado e cidadão, que poderia se beneficiar com a internet, não são observadas na experiência da SEPPIR. Não são disponibilizados serviços on-line ou utilizadas outras ferramentas, como chats, fóruns e listas de discussão. 0 único canal de diálogo é o e-mail. Um canal que proporciona a comunicação apenas entre 0 cidadão e o representante do governo. Com ele, é mais difícil que outras saibam os questionamentos levantados e as repostas emitidas, se emitidas.
Assim, 0 site da SEPPIR consegue atingir apenas um nível de responsividade, proposto por Silva. Responsivo significa ser, de alguma forma, dialógico. Mas nenhum nível é alcançado quando 0 requisito da vez é a porosidade, onde o Estado mostra-se aberto à opinião pública e quando o fluxo vem da sociedade, quando o cidadão é considerado na formulação de políticas. No site da SEPPIR, não há ferramentas que proporcionem aos cidadãos participarem plenamente da produção da decisão política.

Mas há um indicativo de mudança. É o que espera a Coordenação de Comunicação da SEPPIR para o ano de 2012. Segundo Jucinete Maria Machado, em dezembro de 2011, já se executava um planejamento para 0 setor que englobaria, entre outros pontos, mudanças na estrutura de pessoal e na estrutura física, elaboração de planos de ação para a campanha Igualdade Racial é pra Valer ${ }^{11} \mathrm{e}$ modernização das ferramentas de comunicação, incluindo 0 site.

Conforme Machado, a ideia é tornar o site, "mais dinâmico, mais interativo e mais multimídia, que possibilite inserção de vídeos de áudio", por exemplo. Outro desejo do setor de comunicação, diante da intensa utilização do e-mail da SEPPIR pelos cidadãos, é colocar ferramentas que propiciem mais diálogo com o internauta, mas até dezembro de 2011, essas ferramentas ainda 
não tinham sido escolhidas. Sobre isso, a coordenadora de comunicação fala com cautela: "[...] a gente tem que ter uma visão sobre a consequência de você abrir um diálogo como esse. Porque você tem que dá suporte, você tem que monitorar. [...] Se você não monitora uma ferramenta como esse, você perde todo 0 sentido. ${ }^{12}$

Mas, enquanto essa reformulação não chega, 0 site da Secretaria de Políticas de Promoção da Igualdade Racial continua com respostas nulas em relação às exigências de porosidade e com experiências ainda tímidas quando o tema é abrir-se para 0 diálogo com 0 cidadão, reforçar a discutibilidade que caracteriza a esfera pública, inclusive no ambiente virtual. E, apesar de implantar, dentro das suas possibilidades estruturais, ferramentas que objetivam tornar 0 órgão mais transparente, o seppir.gov.br ainda carece de uma publicidade de mais qualidade, com mais atualização e organização dos dados.

Desse modo, a secretaria, através de seu site, não dá grandes contribuições à esfera pública discursiva, onde 0 debate ocupa papel central. Mantêm mesmo suas experiências no que chamamos de esfera de visibilidade pública. Faz isso ao expor dados sobre a equipe, sua história, seus objetivos, ao informar, mesmo com alguns problemas, as atividades realizadas.

\section{Referências}

BEST, Nina Juliette et al. Internet e a participação cidadã nas experiências de orçamento participativo digital no Brasil. Cadernos PPG-AU/UFBA, v. 9, p. 105-124, 2010. Edição especial.

BOHMAN, James. Expanding dialogue: the internet, the public sphere and prospects for transnational democracy. The Sociological Review, v. 52, suplement 1, p. 131-155, 2004.

CASTELLS, Manuel. Internet e sociedade em rede. In: MORAES, Dênis de (Org.). Por uma outra comunicação. Rio de Janeiro: Record, 2003. p. 255-287.

COSTA, Sérgio. As cores de Ercília: esfera pública, democracia, configurações pós-nacionais. Belo Horizonte: UFMG, 2002.

DEAN, Jodi. Why the net is not a public sphere.

Constellations, v. 10, n. 1, p. 95-112, 2003.

GOMES, Wilson. Publicidade, visibilidade, discutibilidade: para uma revisão do conceito de esfera pública política. In: ENCONTRO ANUAL DA COMPÓS, 16., 2007, Curitiba. [Anais....]. Curitiba: UTP, 2007. Disponível em: < http://www.compos.org.br/data/ biblioteca_41.pdf $>$. Acesso em: 29 jun. 2011. Da discussão à visibilidade. In: GOMES, Wilson; MAIA, Rousiley C. M. Comunicação e democracia: problemas \& perspectiva. São Paulo: Paulus, 2008. p. 117-162

Participação política online: questões e hipóteses de trabalho. In: MAIA, Rousiley C. M.; GOMES, Wilson; MARQUES, Francisco Paulo Jamil (Org.). Internet e participação política no Brasil. Porto Alegre: Sulina, 2011. p. 19-45.

HABERMAS, Jürgen. Direito e democracia: entre facticidade e validade. Volume II. Rio de Janeiro: Tempo Brasileiro, 2003. 
INSTITUTO BRASILEIRO DE GEOGRAFIA E

ESTATÍSTICA. Pesquisa Nacional por Amostra de

Domicílios: síntese de indicadores 2009. Disponível em:

$<$ http://www.ibge.gov.br/home/estatistica/populacao/

trabalhoerendimento/pnad2009/pnad_sintese_2009.

pdf $>$. Acesso em: 15 mar. 2011.

JENSEN, Jakob Linaa. Public spheres on the internet: anarchic or government-sponsored: a comparison. Scandinavian Political Studies, v. 26, n. 4, p. 349-374, 2003.

LEMOS, André; ROCHA, Flávio. Governo eletrônico. In: LEMOS, André (Org.). Cidade digital: portais, inclusão e redes no Brasil. Salvador: EDUFBA, 2007. p. 99-112.

LÉVY, Pierre. Pela ciberdemocracia. In: MORAES, Dênis de (Org.). Por uma outra comunicação. Rio de Janeiro: Record, 2003. p. 367-384.

LIMA, Damião Marques de. Comunicação pública e internet: As contribuições para a democracia no novo ambiente de práticas políticas do Governo de Roraima. 220 f. Dissertação (Mestrado em Políticas Públicas e Sociedade) - Universidade Estadual do Ceará, Fortaleza, 2012.

MARQUES, Francisco Paulo Jamil Almeida.

Participação política e internet: meios e oportunidades digitais de participação civil na democracia contemporânea, com um estudo do caso do estado brasileiro. $498 \mathrm{f}$. Tese (Doutorado em Comunicação e Cultura Contemporâneas) - Faculdade de Comunicação, Universidade Federal da Bahia, Salvador. 2008.

Participação, instituições políticas e internet: um exame dos canais participativos presentes nos Portais da Câmara e da Presidência do Brasil. In: MAIA, Rousiley C. M.; GOMES, Wilson; MARQUES, Francisco Paulo Jamil (Org.). Internet e participação política no Brasil. Porto Alegre: Sulina, 2011. p. 95-121.

MATHEUS, Ricardo. Consultas públicas do Governo Federal e Agências Reguladoras. Congresso CONSAD de gestão pública, Brasília, 2009. Disponível em:
< http://www1.seplag.rs.gov.br/upload/Painel_48_ Ricardo_Matheus_formatado.pdf > . Acesso em: 20 ago. 2011.

MAZZOLENI, Gianpietro. La revolución simbólica de Internet. CIC Cuadernos de Información y Comunicación, Madrid, n. 6, p. 33-38, 2001.

MIOLA, Edna. Iniciativas institucionais de deliberação online: um estudo do fórum de discussão do portal da Câmara dos Deputados. In: MAIA, Rousiley C. M.; GOMES, Wilson; MARQUES, Francisco Paulo Jamil (Org.). Internet e participação política no Brasil. Porto Alegre: Sulina, 2011. p. 147-174.

OLIVEIRA, Alicianne Gonçalves de. A questão racial na esfera pública (virtual): a experiência da Secretaria de Políticas de Promoção da Igualdade Racial no governo Dilma Rousseff. $221 \mathrm{f}$. Dissertação (mestrado) - Universidade Federal do Ceará, Instituto de Cultura e Arte, Programa de Pós-Graduação em Comunicação, Fortaleza, 2012.

PAPACHARISSI, Z. The virtual sphere: the internet as a public sphere. New Media \& Society, v. 4, n. 1, p. 9-27, 2002.

PINHO, José Antonio Gomes de. Investigando portais de governo eletrônico de estados no Brasil: muita tecnologia, pouca democracia. Revista de Administração Pública, v. 42, n. 3, p. 471-493, jun. 2008.

ROQUE, Átila. Construção e desconstrução do silêncio: reflexões sobre o racismo e 0 antirracismo na sociedade brasileira. In: PAULA, Marilene de; HERINGER, Rosana. Caminhos convergentes: estado e sociedade na superação das desigualdades raciais no Brasil. Rio de Janeiro: Fundação Heinrich Boll, ActionAid, 2009. p. 259-274. Disponível em: < http:// www.actionaid.org.br/Portals/0/Docs/Caminhos/ caminhos_convergentes\%20completo.pdf $>$. Acesso em: 12 mar. 2011.

ROTHBERG, Danilo. Por uma agenda de pesquisa em democracia eletrônica. Opinião Pública, v. 14, n. 1, p.149-172, jun. 2008. 
SAVIGNY, Heather. Public Opinion, Political

Communication and the Internet. Politics, v. 22, n. 1, p. $1-8,2002$.

SILVA, Sivaldo Pereira. Graus de participação democrática no uso da Internet pelos governos das capitais brasileiras. Opinião pública, Campinas, v. 11, n. 2 , p. 450-468, out. 2005.

Exigências democráticas e dimensões analíticas para a interface digital do Estado. In: MAIA, Rousiley C. M.; GOMES, Wilson; MARQUES, Francisco Paulo Jamil (Org.). Internet e participação política no Brasil. Porto Alegre: Sulina, 2011. p. 123-146.

THOMPSON, John B. A metodologia da interpretação. In: . Ideologia e cultura moderna: teoria social critica na era dos meios de comunicação de massa. Petrópolis, RJ: Vozes. 1999. p. 355-421. 


\section{Racial question and virtual public sphere: an analysis of the site of the Secretariat for the Promotion of Racial Equality}

\section{Abstract}

This paper aims to understand how the organ of the Brazilian Federal Executive linked to issues of race acts on the virtual public sphere. The analysis focuses on the site of the Secretariat for the Promotion of Racial Equality (SEPPIR), linked to the Presidency of the Republic. The purpose is to evaluate the contribution of this site in the formation of spheres of public visibility and discutibility. The article also examines if this experience meets the democratic demands for the digital interface of state: publicity, responsiveness and porosity. To develop these ideas, a qualitative evaluation of the site was made. Also refers to an interview with the professional responsible for the vehicle studied.

\section{Keywords}

Virtual public sphere. The Federal Government. Racial issue.

\section{Cuestión racial y la esfera pública virtual: un análisis de lo sitio de la Secretaría para la Promoción de la Igualdad Racial}

\section{Resumen}

En este artículo se busca entender cómo la institución de lo Gobierno del Brasil relacionado con el problema racial actúa en la esfera pública virtual. Para tanto, analiza el sitio de la Secretaría de Promoción de la Igualdad Racial (SEPPIR), vinculada a la Presidencia de la República. La intención es evaluar la contribución de este sitio en la posible formación de las esferas de la visibilidad y discutibilidad públicas. Este estudio también examina si la experiencia estatal se encuentra con los requisitos democráticos que debe cumplir la interfaz digital de Estado: la publicidad, la capacidad de respuesta y la porosidad. Así se hace una evaluación cualitativa del sitio. También se refiere a la entrevista con el profesional responsable del vehículo estudiado.

\section{Palabras-clave}

Esfera Pública Virtual. Gobierno Federal. Cuestión Racial. 


\section{Expediente}

A revista E-Compós é a publicação científica em formato eletrônico da Associação Nacional dos Programas de Pós-Graduação em Comunicação (Compós). Lançada em 2004, tem como principal finalidade difundir a produção acadêmica de pesquisadores da área de Comunicação, inseridos em instituições do Brasil e do exterior.
E-COMPÓS I www.e-compos.org.br I E-ISSN 1808-2599

Revista da Associação Nacional dos Programas

de Pós-Graduação em Comunicação.

E-compós, Brasília, v.16, n.1, jan./abr. 2013

A identificação das edições, a partir de 2008 ,

passa a ser volume anual com três números.

\section{CONSELHO EDITORIAL}

Afonso Albuquerque, Universidade Federal Fluminense, Brasil Alberto Carlos Augusto Klein, Universidade Estadual de Londrina, Brasil Álvaro Larangeira, Universidade Tuiuti do Paraná, Brasil André Luiz Martins Lemos, Universidade Federal da Bahia, Brasil Ângela Freire Prysthon, Universidade Federal de Pernambuco, Brasil Angela Cristina Salgueiro Marques, Faculdade Cásper Líbero (São Paulo), Brasil Antonio Roberto Chiachiri Filho, Faculdade Cásper Líbero, Brasil Arthur Autran Franco de Sá Neto, Universidade Federal de São Carlos, Brasil Benjamim Picado, Universidade Federal Fluminense, Brasil César Geraldo Guimarães, Universidade Federal de Minas Gerais, Brasil Cristiane Freitas Gutfreind, Pontifícia Universidade Católica do Rio Grande do Sul, Brasil

Denilson Lopes, Universidade Federal do Rio de Janeiro, Brasil Eduardo Peñuela Cañizal, Universidade Paulista, Brasil

Eduardo Vicente, Universidade de São Paulo, Brasil Eneus Trindade, Universidade de São Paulo, Brasil Erick Felinto de Oliveira, Universidade do Estado do Rio de Janeiro, Brasil Florence Dravet, Universidade Católica de Brasília, Brasil Gelson Santana, Universidade Anhembi/Morumbi, Brasil Gislene da Silva, Universidade Federal de Santa Catarina, Brasil Guillermo Orozco Gómez, Universidad de Guadalajara Gustavo Daudt Fischer, Universidade do Vale do Rio dos Sinos, Brasil Hector Ospina, Universidad de Manizales, Colômbia Herom Vargas, Universidade Municipal de São Caetano do Sul, Brasil Inês Vitorino, Universidade Federal do Ceará, Brasil Jay David Bolter, Georgia Institute of Technology Jeder Silveira Janotti Junior, Universidade Federal de Pernambuco, Brasil John DH Downing, University of Texas at Austin, Estados Unidos José Afonso da Silva Junior, Universidade Federal de Pernambuco, Brasil José Carlos Rodrigues, Pontifícia Universidade Católica do Rio de Janeiro, Brasil José Luiz Aidar Prado, Pontifícia Universidade Católica de São Paulo, Brasil Kelly Cristina de Souza Prudêncio, Universidade Federal do Paraná, Brasil.
Laan Mendes Barros, Universidade Metodista de São Paulo, Brasil Lance Strate, Fordham University, USA, Estados Unidos Lorraine Leu, University of Bristol, Grã-Bretanha Lucia Leão, Pontifícia Universidade Católica de São Paulo, Brasil Malena Segura Contrera, Universidade Paulista, Brasil

Márcio de Vasconcellos Serelle, Pontifícia Universidade Católica de Minas Gerais, Brasil

Maria Aparecida Baccega, Universidade de São Paulo e Escola Superior de Propaganda e Marketing, Brasil

Maria Ataide Malcher, Universidade Federal do Pará, Brasil

Maria das Graças Pinto Coelho, Universidade Federal do Rio Grande do Norte, Brasil Maria Immacolata Vassallo de Lopes, Universidade de São Paulo, Brasil Maria Luiza Martins de Mendonça, Universidade Federal de Goiás, Brasil Mauro de Souza Ventura, Universidade Estadual Paulista, Brasil Mauro Pereira Porto, Tulane University, Estados Unidos Mirna Feitoza Pereira, Universidade Federal do Amazonas, Brasil Nilda Aparecida Jacks, Universidade Federal do Rio Grande do Sul, Brasil Osvando J. de Morais, Universidade de Sorocaba, Brasil Potiguara Mendes Silveira Jr, Universidade Federal de Juiz de Fora, Brasil Renato Cordeiro Gomes, Pontifícia Universidade Católica do Rio de Janeiro, Brasil Robert K Logan, University of Toronto, Canadá

Ronaldo George Helal, Universidade do Estado do Rio de Janeiro, Brasil Rose Melo Rocha, Escola Superior de Propaganda e Marketing, Brasil Rossana Reguillo, Instituto de Estudos Superiores do Ocidente, Mexico Rousiley Celi Moreira Maia, Universidade Federal de Minas Gerais, Brasil Sebastião Guilherme Albano da Costa, Universidade Federal do Rio Grande do Norte, Brasil

Simone Maria Andrade Pereira de Sá, Universidade Federal Fluminense, Brasil Tiago Quiroga Fausto Neto, Universidade de Brasília, Brasil Suzete Venturelli, Universidade de Brasília, Brasil Valerio Fuenzalida Fernández, Puc-Chile, Chile

Veneza Mayora Ronsini, Universidade Federal de Santa Maria, Brasil Vera Regina Veiga França, Universidade Federal de Minas Gerais, Brasil

\section{COMISSÃO EDITORIAL}

Adriana Braga I Pontifícia Universidade Católica do Rio de Janeiro, Brasil

Felipe Costa Trotta I Universidade Federal Fluminense, Brasil

CONSULTORES AD HOC

Bruno Campanella, Universidade Federal Fluminense, Brasil

Christa Berger, Universidade do Vale do Rio dos Sinos, Brasil

Edison Gastaldo, Universidade Federal Rural do Rio de Janeiro, Brasil

José Luiz Braga, Universidade do Vale do Rio dos Sinos, Brasil

\section{EDIÇÃO DE TEXTO E RESUMOS I Susane Barros}

SECRETÁRIA EXECUTIVA I Juliana Depiné

EDITORACã̃ ELETRÔNICA I Roka Estúdio
COMPóS I www.compos.org.br

Associação Nacional dos Programas de Pós-Graduação em Comunicação

Presidente

Julio Pinto

Pontifícia Universidade Católica de Minas Gerais, Brasil juliopinto@pucminas.br

Vice-presidente

Itania Maria Mota Gomes

Universidade Federal da Bahia, Brasil

itania@ufba.br

Secretária-Geral

Inês Vitorino

Universidade Federal do Ceará, Brasil

inesvic@gmail.com 